\title{
Behavioral Mimicry in Chinese and Canadian Negotiations: Frequency, Duration and Impact
}

\author{
Zhaleh Semnani-Azad \\ Clarkson University \\ Reh School of Business \\ zsemnani@ clarkson.edu
}

\author{
Katia Sycara \\ Carnegie Mellon University \\ Robotics Institute \\ katia@cs.cmu.edu
}

\author{
Danielle Rice \\ McGill University \\ Department of Psychology \\ danielle.rice@mail.mcgill.ca
}

\author{
Wendi Adair \\ University of Waterloo \\ Department of Psychology \\ wladair@uwaterloo.ca
}

\author{
Michael Lewis \\ University of Pittsburgh \\ School of Computing and Information \\ katia@cs.cmu.edu
}

\begin{abstract}
Negotiation literature stresses the importance of mimicry in improving relational and economic outcomes. Yet, there is a dearth of work examining how culture influences the display and impact of mimicry in negotiations. In this research, we systematically coded behavioral mimicry among Chinese and Canadian dyadic, intracultural, video-taped negotiations. Using cultural theories of high/low context communication, and individualism/collectivism, we predicted and found that low-context, individualistic Canadian negotiators were more direct in their behavioral mimicry by exhibiting higher frequency of postural mimicry, than Chinese negotiators. In contrast, Chinese negotiators were more indirect in their displays of mimicry via longer durations of mirrored postures. Interestingly, gender moderated the effects of culture on the frequency and duration of mimicry. Mimicry led to higher joint gains, only when dyads did not attend to the indirect meanings of the mimicked behaviors. We discuss implications of behavioral mimicry in crosscultural negotiations.
\end{abstract}

\section{Introduction}

Negotiation is an interpersonal, social process, highly dependent on communication. Through verbal and nonverbal cues, negotiators try to resolve conflicts by developing relationships, trust, and engaging in information-sharing and problem-solving [25]. While communication is the driver of the social process in negotiations, only a handful of research has focused on verbal [26, 27] and nonverbal communications [16, 22, $23,28]$ in this context. One particular aspect of nonverbal communication, i.e. mimicry, has been shown to have a profound effect on both relational and economic outcomes in negotiations [16]. Nonverbal mimicry or mirroring reflects instances in which two or more individuals engage in the same set of communication cues at the same time $[5,6]$. Often, people exhibit mimicry in conversations as a subconscious and automatic behavioral process, reflecting liking or affiliation [16]. In a negotiation context, mimicry is thought to improve relations and develop trust, both of which are needed to boost economic outcomes [16].

Mimicry occurs more often in cooperative contexts or in situations where individuals are motivated to engage in a positive interaction with others [4]. Mimicry on its own, also results in the increase of cooperative behavior. In general, there are four major types of mimicry: facial, emotional, behavioral and verbal [e.g. 5, 6, 24]. Across the board, mimicry has been shown to have a positive relationship with rapport, liking, trust and affinity [6]. The positive relational effects of mimicry are attributed to the physical and psychological similarity and convergence. Specifically, when dyadic mimicry occurs, there is an increase of merging and a decrease of distinction between the self and other [5]. Accordingly, both parties are perceived as one unit, which then leads to the perception of trust and rapport. Other positive outcomes of mimicry include higher interdependence, empathy, and prosocial behavior. Regardless of the underlying mechanism associated with mimicry and its positive outcomes, these favorable relational residues are crucial for a successful negotiation.

There is a dearth of work examining mimicry in negotiations, and even more limited work on how culture and gender intersect to influence the frequency and duration of mimicked behaviors. Culture has a profound effect on people's display and interpretation of communication, as it prescribes the appropriate communication style $[29,30]$. For instance, in the Far 
East, compared to Western Europe, more emphasis is placed in the external context such as individual roles and status in displaying and interpreting nonverbal cues. Culture reflects a set of beliefs, values and norms practiced by a social group, distinct from other social groups [30]. It is reasonable to assume that culture also influences the way communication is mimicked. Similarly, gender norms have a profound effect on the communication style appropriate for men and women. Thus, it is plausible that gender norms will further influence behavioral mimicry. This is yet to be examined, particularly in a negotiation context. The current research examines the influence of cultural factors on mimicked behaviors in negotiations, and the impact in intracultural negotiations. We also examine the intersecting role of gender norms in further influencing mimicry in negotiations.

\section{Mimicry in Negotiations}

Mimicry is defined as the synchronization between the speech and body movements of two interacting partners [5]. Behavioral mirroring or mimicry is a category of nonverbal interpersonal dynamic where people unconsciously adjust the timing and content of physical movements in a manner that mirrors the behaviors exhibited by their interaction partner $[5,6]$. Mimicry within social interactions has looked for links between mimicry and rapport, liking, agreement, reciprocity and persuasiveness. For instance, Chartrand and Bargh (1999) observed a positive relationship between the mimicry of nonverbal behavior and facial expressions and liking others in social interactions. Specifically, the more individuals liked their interlocutor, more perspective taking and nonverbal mimicry took place [5]. A side from liking and affiliation, mimicry has been shown to improve persuasiveness. In a study by Van Swol (2003) a confederate mirrored nonverbal behaviors, as opposed to not, was viewed as more persuasive and confident [24]. From a verbal perspective, Language Style Matching (LSM) has been positively related to liking and social integration [2], through conversational engagement.

In a negotiation context, researchers have examined the influence of behavioral and verbal mimicry. Behavioral mimicry is the adoption of posture and motor movements, while verbal or linguistic mimicry reflects the mirroring or synchronization of verbal speech patterns and vocal paralanguage [6]. Negotiation is a mixed motive interaction that combines both cooperative and competitive strategies and approaches [13]. Negotiators can increase economic gains and reach an optimal outcome by expanding the pool of resources they are negotiating about. This can result in an integrative solution, which requires negotiators to consider the interests and goals of all the negotiation parties. This will enable negotiators to realize shared interests and differences in priorities. Via the trade-off of issues and the realization of compatible issues, negotiators can reach a more optimal negotiation outcome. The path to such realization requires cooperation, trust and rapport. Prior work that examined mimicry in negotiations, based their theoretical framework on research in interpersonal mimicry. These few studies found that mimicry can be beneficial in negotiations as it increases engagement and involvement [19], liking [5], and persuasiveness [24]. These elements foster cooperation and trust, which help improve negotiation outcomes.

Behavioral mimicry has been shown to elicit positive benefits for both relational and economic outcomes through trust and liking, thereby improving individual and joint gains in complex negotiations [16]. Across two experiments, Maddux and colleagues (2008) randomly assigned negotiators to a mimicry or control conditions. In the mimicry condition, negotiators were instructed to strategically mimic their partner, where in the control group individuals focused on their planning documents. The researchers found that $67 \%$ of dyads that engaged in mimicry reached a deal and expanded the joint gains, whereas only $12.5 \%$ of the control conditions reached an agreement that increased joint gain. This research exemplifies how mimicry is able to facilitate interpersonal negotiations and increase joint gain.

Verbal or linguistic mimicry is also associated with favorable negotiation outcomes in face-to-face and virtual interactions. For instance, when observing interactions between police negotiator and hostage taker in nine protracted crisis negotiations, Taylor and Thomas (2008) found that successful negotiations were highly correlated with higher levels of linguistic style matching, or the coordination and synchronization of words. In virtual interactions, the frequency of verbal mimicry associated with reciprocated utterances lead to higher individual gain, particularly if the mimicry occurred in the first five minutes of the interaction. Moreover, vocal mirroring along with other conversational activities, accounted for $30 \%$ of the variance contributing to the individual outcome. In another series of experiments, researchers found that dyadic linguistic mirroring, particularly in the first ten minutes of an online negotiation, lead to higher individual gain, with trust being the mediating factor [16]. These findings illustrate the link between mimicry and trust (potentially stemming from liking and affiliation), which is ideal for fostering a favorable negotiation outcome. 
However, behavioral mirroring within the negotiation setting has not yet been viewed from a cross-cultural perspective. It is important to consider this component of mimicry because negotiating with individuals from other cultures requires an understanding of the other party's communication and interaction norms [1]. Based on these differences it would be advantageous to consider specific behaviors that are mimicked within cultures to ensure mirroring provides the positive outcomes during cross-cultural negotiations, which have been previously viewed in the Western negotiation setting.

\section{Culture, Nonverbal Communication, and Negotiation}

Culture is a causally distributed pattern of mental representations, public expressions and resultant behaviors in ecological contexts [17]. Culture plays a role in cognition, goals, motivation and communication styles which individuals portray both verbally and nonverbally. Those who belong to similar cultural groups may have automatic agreements with regards to communication, causing interactions to be interpreted in a similar manner. Particularly, culture has been shown to influence the displays and social meanings attached to nonverbal cues.

Nonverbal communication can be defined as behaviors other than words themselves, which form a socially shared coding system [8]. Ting-Toomy (1999), stated nonverbal cues can express messages that verbal communication cannot. Nonverbal behaviors contain various messages that can be interpreted in a multitude of ways within a social interaction such as a negotiation.

Prior research illustrated how individuals within cultures interpret the meanings of nonverbal behaviors while engaging in a negotiation. For example, a study done by Semnani-Azad and Adair (2011, 2013) identified several nonverbal cues with universally shared meanings across Easterners and Westerners, as well as several nonverbal cues with distinct social meanings and interpretations. Cultural differences noted by Semnani-Azad and Adair (2011) found Canadian negotiators used posture to distinguish level of involvement by demonstrating rigid posture when actively involved, and leaning back in a relaxed manner when passively involved. When perceiving their counterpart in a negative light, Canadians were more likely to avoid eye contact while; Chinese negotiators engaged in eye contact and leaned back. When conveying dominance, Canadian negotiators held a rigid posture with a straight back, while this same behavior conveyed submissiveness by Chinese negotiators $[22,23]$.
Based on the noted findings, mimicry within negotiations may portray various nonverbal messages that the behavior is not intended to elicit. For example, if a Canadian were to mimic a posture of leaning back, which is associated with negative affect in the Chinese culture, it may result in negative interpretations rather than an increase of liking. Although prior research illustrated a positive relationship between strategic behavioral mimicry and negotiation outcome [16], these findings have not been examined across cultures. With this reality, there is potential for negative consequences of mimicking behaviors with negative social meaning (e.g. passive involvement behaviors). Since, recent research has shown unconscious mimicry to be an important factor in negotiations [16] and nonverbal behavior studies have demonstrated differences in interpretation of behaviors [22, 23], we examined mimicry in cross-cultural negotiations; more specifically, postural mimicry of Canadian and Chinese, males and females, engaging in intracultural negotiation.

\subsection{Mimicry, High Context/Low Context in Culture}

Communication styles are behaviors that occur in the way one's verbal and nonverbal messages interact to signal how meaning should be interpreted, filtered and understood [20]. These styles have been shown to relate to high and low context cultures, which are seen within collectivist and individualist cultures. Low context cultures, typically Westerners, engage in explicit direct information exchange and are more likely to be dominant and animated in their communication styles [20]. This can further be connected to the reality that Westerners are more individualistic and are socialized to express their inner thoughts and feelings to realize their individuality by expressing themselves through actions and words [11]. By focusing on the self, Westerners demonstrate their unique thoughts and feelings openly by preferring more direct strategies of communication [11]. In contrast, high culture context, usually East Asians, engage in implicit and indirect communication and rely on more indirect communication methods as expression of one's thoughts are neither encouraged or viewed positively [11]. It was suggested this may be a reflection of their collectivist culture and having an interdependent self with more sensitivity to the needs and feelings of others in one's group $[9,18]$. Since low context cultures use more direct and explicit communication which is positively associated with independence [31], while indirect and implicit behaviors are positively linked with interdependence in high context cultures [20], we expect Canadian 
negotiators to engage in more nonverbal behaviors than Chinese negotiators, furthermore, allowing for more overt and visible mimicry to occur in the Canadian dyads.

Hypothesis 1: Canadian negotiators will likely display higher instances of mimicked behaviors than East Asian negotiators.

\section{Culture, Gender and Mimicry}

In Western culture, women's sense of self is more directly linked to close relationships in comparison to men's identity [7]. Relational interdependence has been shown to influence behavior [2,7]. This can be demonstrated within social interactions as Lydon (1999) found relationally interdependent individuals are more likely to engage in pro-relationship behaviors [7]. Crockett and colleagues (2007) found that women are more likely than men to have relational selfconstrual. These results were also demonstrated in a role-playing study where women and men were rated on their expressiveness, and results of each expressiveness category was rated higher for women who engaged in more expressive behaviors compared to men [15]. Van Baaren and colleagues (2003), found that individuals with an interdependent self-construal performed the most amount of mimicry in an interaction with a confederate and those with independent self-construal engaged in the least amount of mimicry. Based on this research and findings from Crocket and colleagues (2007), stating women are more likely to have a relational self-construal than men, during negotiations women may seek relational connections with their partner and may unconsciously behave accordingly as individuals with interdependent self-construal and strive for affiliation and liking through increased mimicry behaviors. Therefore, we predict females are more likely to mimic partner's behavior in comparison to males.

Hypothesis 2a: Female negotiators will engage in more behavioral mimicry in comparison to male negotiators.

While looking at women, a focus on the female East Asian negotiators can also be considered. These individuals are from a culture with traditionally strict roles for females. The Chinese father and husband hold increased power over the mother and wife [12]. In particular, the function of women is strictly related to roles of reproduction and housework, which is a sharply defined gender role placing women in stereotypical female positions [12]. Women were rooted in the domestic realm and the traditional roles for Chinese women are expected to demonstrate femininity through these roles [12]. With this normality, women may be seen as living in a "separate sphere" from males, and therefore strive to fulfill and maintain their domestic task-role as a traditional female which is also related to maintaining a relational self-construal as previously noted. With the additional pressure for East Asian women to uphold their traditional gender role, these individuals may automatically demonstrate greater characteristics of relational interdependence.

Traditional gender roles promote females' characterization of self-construal as being more relational than men [10]. Men's gender roles involved hunting and gathering while women's roles were largely based around raising offspring, which is a highly relational task [10]. Theorists suggest cultural differences may be seen within the relational dimensions of self-construal for women [10, 33]. Based on the previous findings relating to the emphasis on gender roles that the East Asian culture promotes, we expect the female Chinese negotiators will mimic more than Canadian female negotiators due to their increased pressure for relationship building.

Hypothesis 2b: Chinese female participants will likely illustrate more behavioral mimicry in comparison to Canadian females.

\section{Method \\ 5.1. Participants and Design}

The sample was composed of 82 participants for a total of 41 dyads. Participants were from East Asian ( $\mathrm{N}=48)$ and Canadian ( $\mathrm{N}=34)$ cultural backgrounds. All North American participants were born in Canada and identified with the North American culture. All East Asian participants were Chinese born and raised in an China, lived in Canada for less than 10 years, and identified with their ethnic culture. Research Design This study involved a 2 (Culture: Chinese, Canadian) $\mathrm{x}$ 2 (Gender: Female, Male) factorial design. The nonverbal behavior category of posture was isolated and mimicry was focused on with frequency of mimicry behaviors, duration of mimicry overlap and lag time on a per second basis, serving as the dependent measures.

\subsection{Materials}

5.2.1. Negotiation Simulation. The video recordings viewed were from a previous study conducted by Semnani-Azad and Adair (2011). Participants engaged 
in an intracultural negotiation occurring between individuals of the same gender and culture. Participants were given details of their role, position, goals and the negotiation interaction. The simulation involved participants negotiating to reach an agreement as to how much money to invest in a new catering business either as a chef or an entrepreneur. This negotiation case, "At Your Service," the two roles of chef and entrepreneur needed to discuss four issues regarding the space they would rent, the van they would rent, and the quality equipment kitchen equipment they would lease. Participants had 15 minutes to prepare and up to 30 minutes to engage in the negotiations. All interactions were video-taped.

5.2.2. Coding of Nonverbal Behavior. Participants' negotiation interactions were videotaped and the duration of mimicry behaviors were coded, specifically concentrating on different postures. Posture categories consisted of: forward lean, lean sideways, lean back, and straight back.

Prior to posture coding, coders were trained to reliably categorize the postural behaviors. Coders were trained to distinguish when participants were leaning sideways, leaning back, leaning forward or had a straight back and at which severity the dominant behavior would switch, without considering unrelated body movements such as hand movements. Coders were of East Asian and North American descent. They completed practice sessions and began coding sessions once reliability reached a mean Kappa of 0.89. All sessions were observed while sound was muted in order to concentrate only on posture without taking other factors into consideration. Coders focused on each participant in the interaction separately. The video sessions were first viewed while categorizing behavior for one participant and then the video was watched again to classify the behaviors while only focusing on the second participant. Coders used a systematic micro coding approach measured on a per-second basis for increased consistency and accuracy between sessions. Behavior classification was documented on excel files to be further examined once all posture coding was complete.

5.2.3. Coding of Mimicry. Once all posture coding was complete the files were then split between coders to be transferred into templates aligning the data for each participant in a session in order to classify mimicry and identify duration, overlap and lags of mirroring behavior. After the data was transferred, coder's colored the mimicry behavior on excel files to isolate the mimicry behaviors and view the dependent variables. Coders received training on protocol for transferring the files to templates as well as highlighting mimicked behaviors. We employed a match-mismatch postural coding scheme for detecting mimicry. Frequency of mimicked behaviors was captured by the total count of mimicked instances. Lag time, was defined as the gap in which the mimicry occurred. More specifically, the time difference between one participant exhibiting a postural behavior until the second participant (negotiation partner) mimicked that behavior. Overlap was defined as the total duration of an overlap of mimicked posture amongst negotiators. Hence, matching of posture behaviors amongst dyads. Frequency, lag time, and overlap were the dependent measures viewed during analysis.

\section{Results}

\subsection{Culture and Gender Differences Impacting Frequency of Mimicry}

Instances of mimicry were viewed at a dyadic level rather than on an individual participant basis. A series of univariate analysis of variance general linear model were conducted to examine the results for all hypotheses. In all our analyses, we controlled for time spent negotiating on a per second basis due to the fact that those who engaged in longer negotiations had greater opportunities to demonstrate mimicry. Therefore, time was a covariate in order to eliminate this possibility.

6.1.1. Hypothesis 1. We predicted that Canadian negotiators would exhibit more mimicked behaviors than East Asian negotiators (H1). Results showed a marginal main effect of culture on the frequency of postural mimicry $(F(1,35)=2.56, p=0.1)$. Mimicry behaviors were demonstrated on more occasions for Canadian participants $(\mathrm{M}=6.61, \mathrm{SE}=0.71)$ in comparison to East Asian participants $(\mathrm{M}=5.05$, $\mathrm{SE}=0.59)$. There were no significant gender differences in the frequency of mimicked behavior $(F(1,35)=$ $0.264, \mathrm{p}>0.05)$. However, a significant Culture $\mathrm{x}$ Gender interaction $F(1,35)=7.40, p=0.01)$ was observed. This interaction partially supported H1, where, Canadians would mimic more than East Asians, yet this was only true for males and not females (see Figure 1). Frequency of mimicked behavior was higher for North American males $(\mathrm{M}=7.59, \mathrm{SE}=0.87)$ than East Asian males $(\mathrm{M}=3.62, \mathrm{SE}=0.78)$. Yet we did not observe a significant cultural difference for mimicked behavior amongst the female negotiators. 


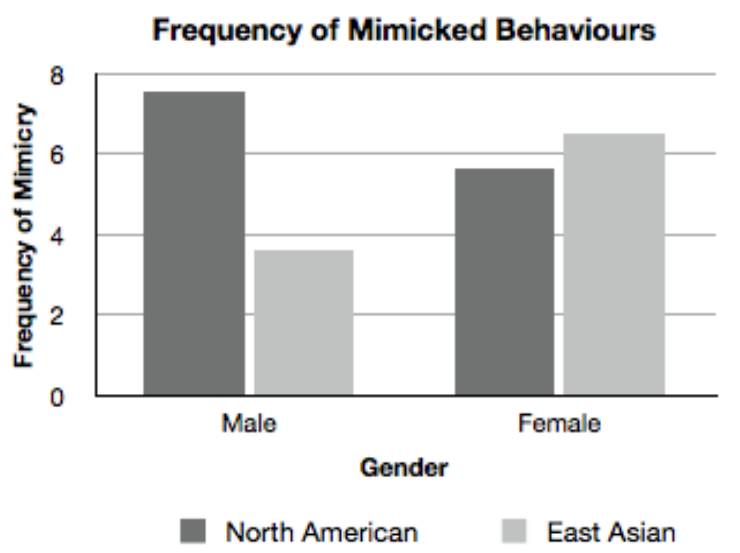

Figure 1. Gender by Culture: Frequency of Mimicry Behaviors

6.1.2. Hypothesis 2. To examine our second hypothesis, we measured duration of overlap for mimicked behaviors and the lag time to examine a potential main effect of gender that females will have higher levels of mimicry than males (H2a) and an interaction with East Asian females engaging in the highest level of mimicry compared to the other conditions (H2b). Results showed no significant difference between the duration of overlap of mimicked behaviors amongst male and female negotiators $(\mathrm{F}(1,35)=0.03, \mathrm{p}>0.05)$, as well as lag time $(\mathrm{F}(1,35)=0.27, \mathrm{p}>0.05)$. Moreover, we did not find a main effect of culture for the overall duration $(\mathrm{F}$ $(1,35)=0.38, \mathrm{p}>0.05)$ or for lag time $(\mathrm{F}(1,35)=1.93$, $\mathrm{p}>0.05)$. Thus, H2a was not supported.

However, we did observe a marginal Culture $\mathrm{x}$ Gender interaction for the duration of overlap ( $\mathrm{F}(1$, $35)=3.52, \mathrm{p}=0.06)$ as well as lag time $(\mathrm{F}(1,35)=2.21$, $\mathrm{p}=0.1$ ), partially supporting $\mathrm{H} 2 \mathrm{~b}$ (see Figure 2). East Asian females were found to be engaging in higher levels of mimicry through shorter lags in mimicry $(\mathrm{M}=138.83, \mathrm{SE}=45.17)$ especially in comparison to North American females $(\mathrm{M}=279.62, \mathrm{SE}=56.63)$. This decrease was also seen when comparing lag time of East Asian females to East Asian males ( $\mathrm{M}=184.48$, $\mathrm{SE}=45.17)$ and Canadian males $(\mathrm{M}=186.18, \mathrm{SE}=$ 45.87). Duration of overlap results demonstrated a similar pattern with East Asian females' duration of overlap $(\mathrm{M}=289.94, \mathrm{SE}=61.67)$ being especially higher than Canadian females overlap results $(\mathrm{M}=126.83, \mathrm{SE}=$ 77.32) and also higher than East Asian males $(\mathrm{M}=181.03, \mathrm{SE}=56.45)$ and slightly greater than Canadian males overlap ( $\mathrm{M}=257.65, \mathrm{SE}=62.63)$.

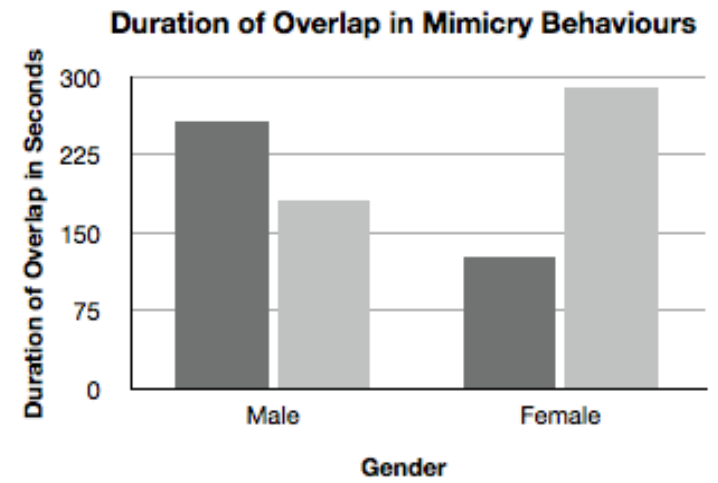

North American

East Asian

Figure 2. Culture by Gender: Duration of Overlap in Mimicry Behaviors

This marginal interaction of lag time in combination with the marginal interaction of overlap lends support for East Asian females engaging in increased mimicry for longer periods of time than Canadian females. When focusing on lag time and duration of overlap in mimicry result for females, H2b is supported with the findings that East Asian females engaged in longer occurrences of mimicry with decreased lag times.

Our findings identified a significant Culture by Gender interaction in frequency of mimicked behaviors where North American males engaged in the highest level of postural mimicry, while East Asian males scored the lowest. We did not observe significant cultural differences in frequency of mimicry amongst female negotiations. Overall, we did not find gender differences in the duration of overlap in mimicry, and lag times between mimicked instances. Yet, a marginal Culture by Gender interaction in duration of overlapped mimicry and lag time suggests that East Asian females, although they did not have a lot of mimicked instances as illustrated in the frequency results, had the longest duration of overlapped mimicry and shortest lag time compared to North American female and male dyads.

\section{Discussion}

The purpose of this research was to consider cultural and gender differences of postural mimicry in negotiations. We investigated culture and gender differences in mimicry based on frequency, overlap, and lag time of mirroring behaviors. We found support for our predicted cultural difference in the frequency of mimicked behavior, such that, North American males 
showed increased frequency of mimicry than East Asian males, which may be linked to North Americans living in a low context culture. Low context cultures demonstrate more overt and direct communication while high contexts cultures use more implicit contextual cues and indirect styles of communication [9, 32]. East Asians are less likely than individuals from a low context culture to display overt nonverbal cues because of their cultural norms of restraint and reserved inward reactions during interactions [9] Based on this knowledge, our findings of Canadian males demonstrating more mimicry may be due to their more overt patterns of communication, which provide more opportunities to engage in mimicry of posture.

This can be linked to potential misinterpretations (or unsuccessful mimicry) in intercultural negotiations, where if an East Asian negotiator were to mimic a Canadian, the mimicry may be subtler and much more indirect to the extent that the Canadian from a low context culture may not (consciously or unconsciously) pick up on the mimicry. This would not allow the East Asian individual mimicking or the negotiating parties to experience the benefits that mimicry can provide. Additionally, we found East Asians demonstrated increased overlap and decreased lag time of mimicry behaviors, especially amongst female negotiators. This may be due to East Asian women's sense of duty to fulfill their gender role as seeking relationships, which can unconsciously occur by mimicking behaviors to increase liking.

These findings match prior research by Chartrand, and colleagues (2005), which found that humans unconsciously increase mimicry behaviors in order to affiliate with others. When interactional partners share the goal to affiliate, they engage in increased mimicry behaviors [6], which may have been a shared goal of East Asian female dyads during the negotiation task. These results may provide East Asian females with an edge in negotiations in comparison to Canadian females who demonstrated the least mimicry as well as more gaps between mimicry. With the knowledge that Canadian females demonstrated much less mimicry than any other category of individuals, it may be found that this group of individuals is failing to gain from the benefits mimicry has to offer. This should be taken into consideration as women and men are both involved in negotiations for certain careers. If Canadian women are not experiencing the gains that males are in negotiations, others may begin inferring that females are less competent within a negotiation setting. This reality may add an additional aspect to the stereotype threat that women may already consider during negotiations.

Gender relevant stereotypes are tied to perceptions of successful and unsuccessful negotiators, specifically, feminine traits are perceived to be ineffective for negotiators $[13,14]$. If Canadian women are not unconsciously engaging in mimicry perhaps they could be taught to strategically mimic with the knowledge of cross cultural norms so they can have the opportunity to gain the full range of benefits mimicry can offer. Many traits equated with negotiation success involve effective communication and listening skills $[13,14]$ which women can improve and activate in order to gain an advantage as a negotiator.

Our findings suggest there are both culture and gender differences when viewing mimicry within a negotiation setting. Results furthered previous research about mimicry and affiliation goals and suggest there may be cultural differences based on one's goal to affiliate to fulfill their gender role. The results also add to prior research by demonstrating differences of mimicry patterns within genders and cultures in relation to frequency, duration of overlap and lag time. It further builds on mimicry research by adding the dynamic of same-gender, intracultural Canadian and East Asian dyads in order to begin research examining mimicry across cultures.

By researching cultural differences in nonverbal mimicry we can predict when miscommunication may arise in cross-cultural negotiations. Previous studies have not viewed the potential negative consequences of behavioral mimicry that may result in dislike and conflict rather than increased liking that has been consistently stated in previous research. Gaining this insight about mimicry is essential so that negotiators can understand which behaviors convey positive or negative aspects across cultures and mimic more consciously because of this. Information on nonverbal communication and mimicry could be used to train those who often negotiation with members of different cultures in order to enhance effective communication and overall efficiency of intercultural negotiations.

\subsection{Limitations and Directions for Future Research}

On the whole, a few general limitations of this research is that only undergraduates were sampled in this study which is hardly representative of the population, so preliminary findings that were generated would have to be replicated in other samples such as in business managers or negotiators. Also, with a greater sample size in general, results may have become more prominent. When the study was conducted it took place in a lab setting so effects may be more conservative in comparison to negotiations that take place during real negotiations. Furthermore, having results split between three dependent measures of mimicry may add a level 
of difficulty in determining which variable should be focused on to obtain the most accurate portrayal of mimicry.

The study measured frequency, overlap and lag time of mimicry behaviors, however interpreting the meaning behind these behaviors may be ambiguous. Future studies could involve answering questions before and after the interaction to determine if increased mimicry really led to increased liking and affiliation and if participants had reacted to the mimicry in an overall positive or negative way. Moreover, there are potential areas of miscommunication between communication styles of Canadian and East Asian individuals when coding for mimicry. Since we viewed mimicry in posture, which is a macro-level behavior, there may be additional instances of mimicry occurring for East Asian participants which are more indirect and subtle for example in hand movements, or other areas which posture coding would have overlooked, resulting in missed opportunities to record examples of mimicry for East Asian participants. Our results did match low context culture expectations with Canadians engaging in more mimicry behaviors however the ability for coders to notice overt mimicry is greatly increased in comparison to subtler movements of posture, which may have been overlooked for East Asian participants. Future research can focus on mimicry within more micro behaviors with the attempt to catch all aspects of mimicry being displayed for individuals of both cultures.

Our results revealed the greatest mimicry occurrences being exhibited by Canadian males and East Asian females with Canadian women and East Asian men demonstrating the least mimicry in all three measures of mimicry viewed. Perhaps hypothesizing within culture does not fully consider all aspects of a group such as only considering prior research of how Canadians are more direct in communication does not take into account the additional reality that women often use more indirect strategies of communication in comparison to men [4-6]. It is possible that the use of direct or indirect strategies is a function of both gender and individualism and collectivism, rather than merely a function of either gender or individualism and collectivism alone [2]. For future studies it may be essential to isolate these aspects when considering culture and gender as an independent variable in order to view the intricacies of prior results more thoroughly.

Another piece of prior research that could be considered when reviewing the results of East Asian females demonstrating the greatest duration of overlap time and least lag time between behaviors is research done about perspective taking. Chartrand and Bargh (1999) found individual differences in perspective taking influence the extent that communicators engage in mimicry. They noted that high-perspective takers naturally manage social interactions with increased mimicry behaviors and established a link between perspective taking and mimicry [5]. A study by $\mathrm{Wu}$ and Keysar, (2006) found Chinese participants demonstrated much greater perspective taking and paid particular attention to behaviors and interpreting actions of others. This may be an additional point to consider with findings of East Asian females in addition to their gender roles. As one limitation of considering gender roles is the reality that we categorized those who would be high in fulfilling gender roles as females, when an additional consideration could be one's femininity and sex role orientation, rather than categorizing all East Asian females as having increased pressure to fulfill gender roles, those who are high in femininity and sex role orientation may find themselves at the higher end of mimicry in comparison to one who views themselves less feminine. It could be useful to consider both variables of gender and sex roles when considering gender differences.

Future research can consider viewing lag time over the entire course of the negotiation rather than viewing an average. This could be useful to view any patterns that may develop across the interaction such as whether lag time between mimicked behaviors is increasing or decreasing. Since when mimicry takes place communicators feel an increased connection to one another [3], in theory, liking would be increasing during a negotiation interaction which would therefore suggest mimicry would begin to occur with decreased lags between mimicked behaviors. While affiliation is increasing and a relationship is developing within the dyads, lag time between behavioral mimicry occurrences may become shorter as the negotiation progresses. Future studies can examine lags across the whole interaction in order to gain insight on this topic.

\section{Acknowledgment}

This research has been sponsored by ARI W911NF-16$1-0514$.

\section{References}

[1] Adair, W. L., \& Brett, J. M. (2005). The Negotiation Dance: Time, Culture, and Behavioral Sequences in Negotiation. Organizational Science, 16, 33-51.

[2] Ang, R.P. \& Kuo, E.C. (2003). Effects of gender effects of gender and individualism-collectivism on directness of refusal. South Pacific Journal of Psychology, 14. 
[3] Bavelas, J. B., Black, A., Lemery, C. R., \& Mullett, J. (1986). "I show how you feel": Motor mimicry as a communicative act. Journal of Personality and Social Psychology, 50, 322-329. doi:10.1037/0022-3514.50.2.322

[4] Beatty, K.D. (2009). Mediated chameleons: an integration of nonconscious behavioral mimicry and the parallel process model of nonverbal communication. Unpublished manuscript, University of North Texas, Texas, United States of America.

[5] Chartrand, T. L., \& Bargh, J. A. (1999). The chameleon effect: The perception-behavior link and social interaction. Journal of Personality and Social Psychology, 76(6), 893910. doi:10.1037/0022-3514.76.6.893

[6] Chartrand, T. L., Maddux, W., \& Lakin, J. (2005). Beyond the perception-behavior link: The ubiquitous utility and motivational moderators of nonconscious mimicry. In R. Hassin, J. Uleman \& J. A. Bargh (Eds.), The new unconscious (pp. 334-361). New York: Oxford.

[7] Crockett, E. E., Loving, T.J., Le, B. Korn, M.S. (2007). Predicting women's and men's reactions to geographic separation: relational interdependence matters. Unpublished manuscript, The University of Texas at Austin, Haverford College, United States of America.

[8] Ekman, P., \& Friesen, W.V. (1975). Unmasking the face: A guide to recognizing emotions from facial clues. Engkewood Cliffs, NJ: Prentice Hall.

[9] Hall, E. T. (1987). Hidden differences-doing business with the Japanese. New York: Anchor Books.

[10] Kashima, Y., Kim, U., Gelfand, M.J., Yamaguchi, S., Choi, S.C., \& Yuki, M. (1995). Culture, gender and self: A perspective from individualism- collectivism research. Journal of Personality and Social Psychology, 69 (5).

[11] Kim, C., Laroche, M., \& Marc, A.T. (2004). The Chinese in Canada: a study in ethnic change with emphasis on gender. The Journal of Social Psychology, 144 (1), Retrieved from doi: 10. 3200/ SOCP. 144. 1. 5-2

[12] Kim, H.S., Sherman, D.K. (2007). "Express yourself": Culture and the effect of self-expression on choice. doi: 10 . $1037 / 0022-3514.92 .1 .1$

[13] Kray, L.J., Galinksy, A., \& Thompson, L. (2001). Battle of the sex: gender stereotype confirmation and reactance in negotiations. Journal of Personality and Social Psychology, 80(6). doi: 10.1037//0022-3514.80.6.942

[14] Kray, L.J., Galinksy, A., \& Thompson, L. (2002). Reversing the gender gap in negotiations: an exploration of stereotype regeneration. Organizational Behavior and Human Decision Processes, 87(2). doi: 10.1006/obhd.2001.2979
[15] Lippa, R. (1998). The nonverbal display and judgment of extraversion, masculinity, femininity, and gender diagnosticity: A lens model analysis. Journal of Research in Personality, 32, 80-107. doi: 10.1006/jrpe.1997.2189

[16] Maddux, W. W., Mullen, E., \& Galinsky, A. D. (2008). Chameleons bake bigger pies and take bigger pieces: Strategic behavioral mimicry facilitates negotiation outcomes. Journal of Experimental Social Psychology, 44(2), 461-468. doi:10.1016/j.jesp.2007.02.003

[17] Markus, H. R., \& Hamedani, M.G. (2007). Handbook of cultural psychology.

[18] Matsumoto, D., \& Kupperbusch, C. (2001). Idiocentric and allocentric differences in emotional expression and experience. Asian Journal of Social Psychology, 4, 113-131.

[19] Niederhoffer, K. G., \& Pennebaker, J. W. (2002). Linguistic style matching in social interaction. Journal of Language and Social Psychology, 21(4), 337-360. doi:10.1177/026192702237953

[20] Park, Y. S., \& Kim, B.S.K. (2008). Asian and European American cultural values and communication styles among Asian American and European American college students. Cultural Diversity and Ethnic Minority Psychology, 14 (1).

[21] Sanchez-Burks, J., Bartel, C. A., \& Blount, S. (2009). Performance in intercultural interactions at work: Crosscultural differences in response to behavioral mirroring. Journal of Applied Psychology, 94(1), 216-223. doi:10.1037/a0012829

[22] Semnani-Azad, Z., \& Adair, W. L. (2011). The display of "dominant" nonverbal cues in negotiation: The role of culture and gender. International Negotiation, 16(3), 451479 .

[23] Semnani-Azad, Z., \& Adair, W. L. (2013). Watch Your Tone... Relational Paralinguistic Messages in Negotiation: The Case of East and West. International Studies of Management \& Organization, 43(4), 64-89.

[24] van Baaren, R. B., Maddux, W. W., Chartrand, T. L., de Bouter, C., \& van Knippenberg, A. (2003). It takes two to mimic: Behavioral consequences of self-construal. Journal of Personality and Social Psychology, 84(5), 1093-1102. doi:10.1037/0022- 3514.84.5.1093

[24] Van Swol, L. M. (2003). The effects of nonverbal mirroring on perceived persuasiveness, agreement with an imitator, and reciprocity in a group discussion. Communication Research, 30(4), 461-480. doi:10.1177/009365020325331

[25] Fisher, R., Ury, W.L. and Patton, B., (2011). Getting to yes: Negotiating agreement without giving in. Penguin. 
[26] Adair, W.L. and Loewenstein, J., (2013). Talking it through: communication sequences in negotiation. Handbook of research on negotiation, 311 .

[27] Weingart, L.R., Olekalns, M. and Smith, P.L., (2004). Quantitative coding of negotiation behavior. International Negotiation, 9(3), pp.441-456.

[28] Bahmani, K., Semnani-Azad, Z., Adair, W. L., \& Sycara, K. (2018). Computer Mediated Communication in Negotiations: The Effect of Intragroup Faultlines on Intergroup Communication and Outcomes.

[29] Holtgraves, T., \& Yang, J. N. (1992). Interpersonal underpinnings of request strategies: General principles and differences due to culture and gender. Journal of personality and social psychology, 62(2), 246.

[30] Holtgraves, T. (1992). The linguistic realization of face management: Implications for language production and comprehension, person perception, and cross-cultural communication. Social psychology quarterly, 141-159.

[31] Park, Y. S., \& Kim, B. S. (2008). Asian and European American cultural values and communication styles among Asian American and European American college students. Cultural Diversity and Ethnic Minority Psychology, 14(1), 47.

[32] Semnani-Azad, Z., \& Nouri, E. (2015). Automatic Interpretation of Negotiators' Affect and Involvement based on Their Non-verbal Behavior. In International Conference on Human-Computer Interaction (pp. 520-529). Springer, Cham.

[33] Semnani-Azad, Z., Sycara, K., \& Lewis, M. (2015). Cooperation in Face and Dignity Cultures: Role of Moral Identity and Gender. In System Sciences (HICSS), 2015 48th Hawaii International Conference on (pp. 275-283). IEEE. 